\title{
Clinical Characteristics and Mid-Term Follow-Up of Patients with Severe Aortic Stenosis and Those not Eligible for TAVI
}

\author{
Gilberto Eder de Oliveira Júnior ${ }^{1}$ (1) and Rogerio Sarmento-Leite $2,3,4,5$ (i) \\ Hospital Nossa Senhora dos Prazeres, ' Lages, SC - Brazil \\ Hospital Moinhos de Vento, ${ }^{2}$ Porto Alegre, RS - Brazil \\ Instituto de Cardiologia do Rio Grande do Sul, ${ }^{3}$ Porto Alegre, RS - Brazil \\ Universidade Federal de Ciências da Saúde de Porto Alegre, ${ }^{4}$ Porto Alegre, RS - Brazil \\ Sociedade Brasileira de Hemodinâmica e Cardiologia Intervencionista, 5ão Paulo, SP - Brazil \\ Editorial referring to the article: Clinical Characteristics and Mid-Term follow-up of Elderly Patients with Severe Aortic Stenosis not Eligible for TAVI
}

Aortic stenosis is an insidious disease with a long-term period of latency. It progresses rapidly after symptoms appear, esulting in a high mortality rate (approximately $50 \%$ in the first 2 years) in untreated symptomatic patients, ${ }^{1}$ with sudden death being common in these individuals.

Approximately $30 \%$ of the patients aged 75 years or over are not candidates for surgical procedure ${ }^{2}$ due to their advanced age, female sex, functional class, operatory emergency, ventricular dysfunction, pulmonary hypertension, previous heart surgery, associated coronary artery disease, among others. In the age range of patients in their 80 s, those who remain in clinical treatment have a survival rate of $65.8 \%$ in the first year and $41.8 \%$ in the second year of follow-up. ${ }^{3}$

Transcatheter aortic valve replacement implantation (TAVI) has become the primary therapy for these patients. It initially demonstrated a non-inferiority as regards patient mortality in one year of follow-up when compared to valve replacement surgery in highrisk patients. In addition, when compared to standard therapy, it has proven that it is necessary to treat 5 patients to prevent 1 death in the period of one year of follow-up. ${ }^{4}$ In the years that followed, it also showed its non-inferiority for intermediate ${ }^{5,6}$ and low $^{7,8}$ surgical risk patients, according to Society of Thoracic Surgery (STS), when compared to conventional surgery.

\section{Keywords}

Aortic Valve Stenosis/surgery; Elderly; Mortality; Transcatheter Aortic Valve Replacement/methods.
According to the guidelines from the American Heart Association (AHA), the American College of Cardiology (ACC), and Society of Thoracic Surgery (STS), ${ }^{9}$ the recommendation for TAVI has been reclassified as Class I; Evidence Level A, in high-risk patients, as well as a treatment option for intermediate-risk patients, classified as Class IIa; Evidence Level B. The most recent European guideline $^{10}$ is, in fact, more liberal in the indication in almost all of the elderly patient scenarios.

In the context of symptomatic severe degenerative aortic stenosis, most patients are elderly and have a predisposition for associated comorbidities. Thus, the deterrents, both for the surgical as well as the less invasive procedures, become more present and significant. Under ideal conditions, TAVI has proven to be the therapy of choice. Nevertheless, some anatomical, clinical, and mainly economic conditions have limited a broader adoption of this technique, which has transformed cardiology as we know it today, in turn engendering a new health challenge in society today.

In an attempt to evaluate the clinical evolution of patients who are not eligible for TAVI, Resende et al., ${ }^{11}$ published a retrospective observational study, which included the analysis of a databank of 475 patients with severe aortic stenosis who were evaluated by the Heart Team to define the proper therapy to be implemented between 2000 and 2017. Considering that $5.26 \%$ of the patients died and that $68.3 \%$ were recommended for TAVI, the remaining 124 patients were considered for the aim of this study. Of these, $25 \%$ were recommended for valve replacement surgery, while in "75\% were opted" for the conservative clinical treatment. 
The results showed that, in the conservative group, the mortality rate was significantly lower when compared to the conventional surgery $(46.2 \%$ vs. $12.9 \%$; $=0.021)$. The clinical factors that stood out concerning this outcome were low weight, advance age, and worsened renal function. These factors are also commonly related to a worse outcomes at any stage of treatment. However, it is also well-known that the worse the scenario, the more benefit a potentially curative strategy can have upon one's quality of life or life expectancy.

TAVI became an ineligible procedure in the Resende et al. ${ }^{11}$ series, considering the following clinical and anatomical factors: a life expectancy of less than one year, the presence of thrombosis in the left ventricle, important symptomatic carotid artery disease, contra-indication for antiplatelet therapy, severe COPD, coronary artery disease with recommendation for surgery, vascular trajectory inadequate due to tortuosity or calcification, and bicuspid aortic valve. It is known, however, that science and technology advance quickly and that many of these frontiers and limits have been overcome. The history of interventionist cardiology has proven this to us, especially in the field of structural pathologies. Nevertheless, the proper recommendation of TAVI, which is based on clinical criteria, adequate diagnostic confirmation, classification of severity, specific anatomical evaluation, and surgical risk, is essential for the success of the procedure. The best decision-making process always resides in the interdisciplinary teamwork and discussion among qualified and trained professionals. Two clinical findings presented here are considered to be absolute contra-indications to this procedure: a life expectancy of less than 1 year and the presence of thrombosis in the left ventricle. Others, however, such as peculiar situations of the trajectory and bicuspid aortic valve, have already been conducted in routine procedures in centers with greater experience and volume.

It is important to highlight that, for the case of bicuspid aortic valves, the elderly of over 80 years of age correspond to nearly $20 \%$ of the surgical cases. Some anatomical characteristics of this pathology, such as the oval form of the ring, the size, and the unequal calcification of the leaflets, confer less predictable results for the use of TAVI. But a recent meta-analysis of 13 observational studies containing data from 758 patients with bicuspid valves showed a $95 \%$ success rate for the device. ${ }^{12}$

Despite the limitations inherent to the study conducted by Resende et al., ${ }^{11}$ as this is an observational design with intrinsic selection biases, the clinical and anatomical aspects presented and the deterrents of TAVI reflect the hold-ups of the real world of healthcare practice in Brazil. Clinical judgment conducted by a Heart Team appears to be of utmost importance in choosing the proper therapy. Therefore, we should continue to work in such a way that more patients can be benefitted and receive universal access to this revolutionary, highly safe, and effective treatment. We are also eager for the possibility of adopting this procedure as a routine technique within the public healthcare network and for all individuals who fulfill the necessary clinical and anatomical criteria to be able to receive this treatment.

The challenges for the incorporation of new technologies are immense. But when science, good judgement, medical management focused on results, and the decision-making body walk hand-in-hand, the goals are more easily achieved. And the natural consequences and those benefitted from these actions are and always will be the patients and society in general.

\section{References}

1. Davies SW, Gershlick AH, Balcon R. Progression of valvular aortic stenosis: a long-term retrospective study. Eur Heart J. 1991;12(1):10-4 doi:10.1093/cxfordjournals.eurheartj.a059815.

2. Iung B, Cachier A, Baron G, Messika-Zeitoun D, Delahaye F, Tornos P, et al. Decision-making in elderly patients with severe aortic stenosis: why are so many denied surgery? Eur Heart J. 2005;26(24):2714-20. doi: 10.1093/eurheartj/ehi471.

3. Jones DR, Chew DP, Horsfall MJ, Chuang AM, Sinhal AR, Joseph MX, et al. Effect of Balloon Aortic Valvuloplasty on Mortality in Patients With Severe Aortic Stenosis Prior to Conservative Treatment and Surgical or Transcatheter Aortic Valve Replacement. Heart Lung Circ. 2020;29(5):719-28. doi: 10.1016/j.hlc.2019.06.717.

4. Smith CR, Leon MB, Mack MJ, Miller DC, Moses JW, Svensson LG, et al. Transcatheter versus surgical aortic-valve replacement in high-risk patients. N Engl J Med. 2011;364(23):2187-98. doi: 10.1056/ NEJMoa1103510.

5. Leon MB, Smith CR, Mack MJ, Makkar RR, Svensson LG, Kodali SK, et al.PARTNER 2 Investigators. Transcatheter or Surgical AorticValve Replacement in Intermediate-Risk Patients. N Engl J Med. 2016;374(17):1609-20. doi: 10.1056/NEJMoa1514616.

6. Reardon MJ, Van Mieghem NM, Popma JJ, Kleiman NS, Sandergaard L, Mumtaz M, et al. SURTAVI Investigators. Surgical or Transcathet.er Aortic-Valve Replacement in Intermediate-Risk Patients. N Engl J Med 2017;376(14):1321-31. doi: 10.1056/NEJMoa1700456.

7. Mack MJ, Leon MB, Thourani VH, Makkar R, Kodali SK, Russo M, et al. PARTNER 3 Investigators. Transcatheter Aortic-Valve Replacement with a Balloon-Expandable Valve in Low-Risk Patients. N Engl J Med. 2019 May 2;380(18):1695-705. Doi: 10.1056/NEJMoa1814052.

8. Popma JJ, Deeb GM, Yakubov SJ, Mumtaz M, Gada H, O'Hair D, Bajwa $\mathrm{T}$, et al. Evolut Low Risk Trial Investigators. Transcatheter Aortic-Valve Replacement with a Self-Expanding Valve in Low-Risk Patients. N Engl J Med. 2019 May 2;380(18):1706-15. Doi:10.1056/NEJMoa1816885. 
9. Otto CM, Nishimura RA, Bonow RO, Carabello BA, Erwin 3rd JP, Gentile F, et al.. 2020 ACC/AHA Guideline for the Management of Patients With Valvular Heart Disease. J Am Coll Cardiol. 2021;77(4):e25-e197. doi:10.1056/NEJMoa1816885.

10. Vahanian A, Beyersdorf F, Praz F, Milojevic M, Baldus S, Bauersachs J, et al. $2021 \mathrm{ESC} / \mathrm{EACTS}$ Guidelines for the management of valvular heart disease. Eur J cardiothorac Surg.2021 Aug 28:ezab.389. doi:10.1093/ ejcts/ezab389.
11. Rezende MO, Santos NSS, Andrade AA, Francischini M, Targino DVD, Souza CS, et al. Clinical Characteristics and Mid-Term follow-up of Elderly Patients with Severe Aortic Stenosis not Eligible for TAVI. Int J Cardiovasc Sci. 2021; 34(5Supl.1):34-40.

12. Reddy G, Wang Z, Nishimura RA, Greason KL, Yoon S-H, Makkar RR, et al. Transcatheter aortic valve replacement for stenotic bicuspid aortic valves: Systematic review and meta analyses of observational studies. Catheter Cardiovasc Interv 2018;91(5):975-83. doi:10.1002/ccd.27240. 